year is not a sufficient time on which to build more than hopes, yet a cessation of the iritis, and a disappearance of the more superficial ocular disease makes one feel that the hopes have some good foundation.

\title{
HYDATID CYSTS OF THE ORBIT
}

BY

\section{J. WOOD}

CAPE TOWN

HYDATID cysts of the orbit are not uncommon in South Africa, and from first to last $I$ have seen a large number of them. It is a possibility to be remembered in all cases of proptosis, and, so far as I know, little is on record to help the operator who finds himself confronted with such a case. In the last three years I have had three cases which have been instructive by reason of the errors made, and it may save others from making similar errors if I relate them.

Hydatid cysts in the orbit fall into two classes according to their position, those which are within the muscle cone and those which are without. The difference is a very practical one, since if the cyst is within the muscle cone, or at the apex of the orbit, the eye will become blind, whereas if it is lateral to the eyeball it probably will not. Moreover, in the latter position operation is comparatively easy, while in the former case it is difficult. Diagnosis is very uncertain short of aspiration, but the negative Wassermann, the absence of inflammation, and of a palpable tumour in most cases, are suggestive if the patient lives in a land where hydatid disease occurs.

The first case came in October, 1920, a coloured girl, P. Japhtha, aged sixteen. There was proptosis of the left eye which had been increasing, with pain, during a month. Vision was six-ninths. No tumour could be felt, but the eye resisted backward pressure. There was no fundus change. I suspected a tumour. Her blood was taken for a Wassermann test, and she was told to return in a week. The test was negative, but the girl did not return till April, 1921. The eye was then pushed forwards almost to the point of dislocation. It had been quite blind for four months, but the cornea was clear enough to allow the fundus to be still seen, and it was apparently normal. Slight neuritis is not uncommon in orbital hydatids.

No tumour.was palpable anywhere, despite the prominence. There was no disease elsewhere. Movements were present but restricted. Under an anaesthetic I explored the orbit, and deeply 
in the apex I tapped a cyst whose clear contents were under pressure, and pushed up the piston of the syringe. An incision was made at the outer upper orbital angle and a slow dissection made backwards. The orbital fat was a great nuisance, only partly. controlled by a bi-valve nasal speculum. The muscles were hardly recognizable, and I divided the superior rectus, stretched out into a membrane, before I recognized it. The white cyst was at last reached in the orbital apex and was removed, piecemeal at first, and the remainder in one pretty big fragment, measuring about an inch by half an inch when floated out in water. The typical cyst wall, like white of egg hard boiled, cannot be mistaken for anything else. As in all the cysts I have seen it was sterile-no daughter cysts.

Much oedema followed but did not last long. The result was surprising. On the third day patient was able to see light, in two weeks she had 6/5, and in three weeks most of $6 / 4$; almost too good for belief. There was some ptosis and loss of upward movement but less than I expected. The result was therefore unexpectedly good.

The second case was seen in February, 1922. A child of three was brought to hospital with the left eye greatly proptosed, the cornea ulcerated from exposure, and practically destroyed. My diagnosis was "probably glioma." Operation, however, showed immediately that the eye was not adherent behind, and it was • removed with ease. When bleeding had lessened, I caught a glimpse of a dark blue cystic looking body in the orbit, but I failed to palpate anything or to see it again. The next day I was informed that the child had a high temperature and was delirious, and I began to think of a ruptured encephalocele. Two days later the temperature went down, and before the end of the week two ruptured clear-walled hydatid cysts were discharged from the orbit. The thick white cyst wall was absent, and they resembled daughter cysts except that there were no traces of heads or suckers.

In December of 1923, I saw the third case, a white woman of 25, Mrs. Roux, who came to the hospital with great prominence of the right eye. Pain in the orbit dated back a year, and proptosis nearly as long. Sight failed from the outer side, and for six months the eye had been wholly blind. No tumour could be felt. Wassermann test was negative. There was no fundus change. I thought first of hydatid, but very unwisely made an exploratory puncture, before I had arranged for special instruments. Hydatid fluid was found deep in the orbit, and remembering my former difficulties I decided to wait. This proved impossible, as by the next day there was intense oedema of the whole orbit with fixation of the eye, and suggestion of early suppuration. Under an anaesthetic I incised at the upper outer angle of the orbit, and dissected down, but owing to the great oedema progress was very slow, and it was 
practically impossible to tell what tissues one was dealing with. As before, the worst trouble was due to the orbital fat, but haemorrhage was also very annoying. The cyst was reached deep in the orbital apex and was removed, first in small pieces and ultimately as a goodsized fragment about an inch by three quarters, but very irregular.

Recovery was very good, and six days after the operation patient could see hand movement. It was, however, only too clear that her right sixth nerve had been damaged, as she had a bad and increasing convergent squint. Before she left hospital she had six sixtieths of vision, and having lost her pain she did not mind the squint.

There are several lessons which I have had to learn in these cases. One must have everything ready for the completion of the operation when one starts to explore the orbit. In my third case I removed nearly 3 c.c. of fluid, in spite of which there must have been a large leak of irritating material into the orbit so that the operation was seriously complicated by the intense reaction.

The second point is that one must have an efficient light. The operation has to be done down in a narrow hole close to important structures, and a small light which will neither shine in the eyes, nor obstruct the vision is essential. I propose to get a reflector made to fit over the end of my Graves' corneal illuminator, so that the tube of the latter may lie flat on the surface and throw the light - just over the edge of the hole. A mirror or head light might be better.

An efficient speculum is necessary to dam back the orbital fat. One will have to remove much of this, but a good long bi-valve speculum would save a lot. Another point is that when one has to work in a small deep cavity one's hands get in the way of one's vision, and angled scissors and forceps are a great help.

The most interesting point of these cases is the extraordinary capacity for recovery of vision after long periods of blindness. I know of three cases where this occurred in eyes blind for many months, though none approached in recovery the first case I have mentioned. The capacity to recover is important, as, where an eye has been blind for months, there might be a temptation to excise it in order to obtain easy access to the orbit.

It would seem that if the visual failure in glaucoma is attributable to the stretching of nerve fibres at the disc margin, a different sort of damage occurs from what happens in these cases of hydatid, since the former is incapable of recovery while the latter is not.

In all of the cases the other eye was unaffected and vision and fields of vision were good.

The early recovery of vision points to the absence of degenerative changes in the nerves which was in agreement with the absence of fundus changes. 